\title{
AGAMA DAN INTEGRASI SOSIAL DALAM PEMIKIRAN CLIFFORD GEERTZ
}

\author{
Mahli Zainudin Tago \\ Universitas Muhammiyah Yogyakarta \\ Maz_tago@yahoo.com \\ Shonhaji \\ IAIN Raden Intan Lampung \\ shonhaji@yahoo.com
}

\begin{abstract}
Abstrak
Artikel ini menelaah hasil penelitian Clifford Geertz tentang keberagamaan masarakat di Mojokuto Jawa Timur. Tema yang diusung dalam artikel ini adalah interelasi antara agama dan masyarakat serta interaksi sosial antara berbagai kelompok sosial yang ada di Mojokuto Jawa Timur. Dari kajian terhadap interrelasi agama dan masyarakat dapat dipahami seberapa jauh pengaruh agama terhadap prilaku relegiousitas masyarakat Jawa, termasuk pengaruh budaya lokal terhadap agama itu sendiri, yang menurut pengamatan Clifford Geertz melahirkan "Agama Jawa". Sementara dari kajian terhadap interaksi dari berbagai kelompok sosial dapat dipahami bahwa, agama, di samping memiliki fungsi integrasi (kohesi sosial) juga menjadi penyebab terjadinya konflik dalam masyarakat. Ketiga varian agama Jawa; santri, priyayi, dan abangan meskipun secara kualitas berbeda dan saling mengklaim bahwa komunitasnya yang paling baik dan benar namun ketiganya masih memperlihatkan nuansa tradisi Jawa. Bahkan, kaum santri yang ketat sekalipun dalam batas-batas tertentu pada kenyataannya masih mentolerir tradisi jawa.
\end{abstract}

Abstract

RELIGION AND SOCIAL INTEGRATION IN THE VIEW OF CLIFFORD GEERTZ: This article explores Clifford Geertz's study on religion among the Mojokuto society in East Java. The themes of this article are, partly, interrelation between religion and society and, partly, the social interaction between various social groups in the area. The study of the interrelation between religion and society identifies the influence of religion on the culture of Java community and vice versa that, in Clifford Geertz observation, had 
given birth what he called "Religion of Java". While the study of interaction of various social groups reveals that religion, in addition to having the function of integration (social cohesion), is also a source of social conflicts. The three variants of Java religion - santri, priyayi, and abangan- though different in qualities and each claims that they are the best and the most correct, are still showing shades of Javanese tradition. In fact, even the tight santry, within a certain limit, still tolerate the Javanese tradition.

Kata Kunci; Agama Jawa, Konflik, Integrasi

\section{A. Pendahuluan}

Penyebaran agama Islam di tanah Jawa pada abad ke-15 dihadapkan kepada dua jenis lingkungan, yaitu budaya kejawen (istana Majapahit) yang menyerap unsur-unsur Hindunisme dan budaya pedesaan. Dalam pada itu, terjadi culture contact, yang kemudian berbuah akulturasi antara dua arus nilai yang sama besarnya, yaitu asimilasi antara ajaran Islam dengan budaya Jawa, baik dalam lingkungan keraton maupun pedesaan.

Dalam perpektif sosio-antropologis, ketika ada suatu agama masuk pada masyarakat lain di luar masyarakat pembentuknya, agama itu akan mengalami proses penyesuaian dengan kebudayaan yang telah ada. Ada kompromi nilai atau simbol dengan kebudayaan asal, sehingga menghasilkan bentuk baru yang berbeda dengan agama atau budaya asal. ${ }^{1}$ Proses akulturasi yang berangsur-angsur sedemikian rupa membuat Islam sebagai ajaran agama dan Jawa sebagai entitas budaya menyatu, dan membentuk sebuah budaya yang berbeda dari budaya asal. Hal in ini disebabkan adanya “fluiditas", pelenturan nilai-nilai lama.

Pengaruh Islam yang begitu besar di Jawa satu sisi, dan kuatnya masyarakat mempertahankan budaya Jawa pada sisi lain, mengharuskan keduanya melebur menjadi satu. Peleburan dan pencampuran demikian yang ditemukan Clifford Geertz dalam penelitiannya di Mojokuto Jawa Timur. Menurut pengamatannya perbedaan pola keberagamaan anatara abangan, santri dan priyayi sangat depengaruhi oleh status sosial dan tingkat kehidupan masingmasing lapisan sosial.

${ }^{1}$ Dadang Kahmad, SosiologiAgama,(Bandung:PenerbitPTRemajarosdakarya, 2002), cet.2, h.74 
Tesis Clifford Geertz tersebut pada perkembangan sejarahnya, di samping mendapatkan penguatan dan dukungan, juga tak kalah serunya mendapatkan serangan dari para antropolog dan sosiolog. Terlepas dari pro-kontra, yang jelas Clifford Geertz telah memberikan investasi yang cukup berarti terhadap konstruksi keilmuan sosiologi agama. Bahkan, melalui ketajaman analisis sosio-antropologisnya yang dibangun selama bertahun-tahun, ${ }^{2}$ ia telah mampu melakukan sebuah upaya rekonstruksi terhadap stratifikasi sosial di Jawa ${ }^{3}$.

Sebagai kerangka acuan diskusi, tulisan ini akan difokuskan pada interelasi antara agama dan masyarakat serta interaksi sosial antara berbagai kelompok sosial yang ada, di Mojokuto Jawa Timur. Dari kajian terhadap iterrelasi agama dan masyarakat diharapkan dapat dipahami pengaruh agama terhadap prilaku relegiousitas masyarakat Jawa, demikian juga sebaliknya akan diketahui pengaruh budaya lokal terhadap agama, yang menurut pengamatan Clifford Geertz melahirkan "Agama Jawa". Demikian halnya dengan kajian terhadap interaksi sosial dari berbagai kelompok sosial diharapkan dapat dipahami bahwa, agama, di samping memiliki fungsi integrasi( kohesi sosial) juga menjadi penyebab terjadinya konflik dalam masyarakat.

\section{B. Sejarah Intelektual Clifford Geertz}

Clifford Geertz lahir di San Fransisco, California tahun 1926 dan meninggal dunia pada tanggal 31 Oktober 2006 dalam usia 80 tahun. Setelah menyelesaikan SMA, ia mempelajari filsafat hingga mendapat gelar B.A. tahun 1950 dari Antioch College di Ohio. Selanjutnya

${ }^{2}$ Menurut Daniel L. Pals, ide dan gagasan besar Clifford Geertz berkembang dibawah pengaruh dua pengaruh utama; tradisi Antropologi Harvard University, Amerika Serikat, yang independen dan kuat, dan tradisi sosiologis Max Weber melalui bimbingan Talcott Parsons. Lihat. Daniel L. Pals dalam, Seven Theories of Religion, (Jogjakarta: Penerbit Qalam, 2001), cet.1. h. 401 dan 406

${ }^{3}$ D.H. Burger melihat stratifikasi social Jawa ada tiga; raja, bangsawan dan petani, lihat bukunya, Structural changes in Javanese Society, The Supra Village Sphere, terj. H. Palmier. Rangkaian terjemahan (New York: Modern Indonesia project, Cornell Univercity, 1956), h. 12. Dalam perkembangan sejarahnya stratifikasi social di Jawa berubah menjadi empat tingkat; ndoro (bangsawan), priyayi ( birokrat), dagang dan saudagar (pedagang), dan wong cilik (rakyat kecil), R.M. Koentjaraningkrat, Pembicaraan buku Clifford Geertz, The religion of Jawa, Majalah Ilmu-ilmu Sastra Indonesia, I, no.2, September 1963, h. 188-198. 
beliau melanjutkan studi antropologi di Harvard Univercity, di sinilah ia banyak dituntut kerja lapangan sebagai landasan bagi konstruksi keilmuannya. Pada tahun kedua bersama-sama dengan istrinya, ia mendapat tugas akademis, untuk mengadakan penelitian masyarakat multi agama di Indonesia (jawa) selama 2 tahun. Penelitian inilah yang selanjutnya menghantarkannya hingga menyandang gelar doktor dari Harvard's Departemen of Social Relations tahun 1956. Keberhasilan Clifford Geertz itulah yang mendorongnya melakukan penelitian di Indonesia yang kedua kalinya (Bali). Setelah menyelesaiakan kerja lapangannya di Bali tahun 1958, beliau diangkat sebagai staf pengajar Universitas California di Berkeldey. Untuk selanjutnya pindah ke University of Chicago selama 10 tahun (1960-1970). Pada tahun 1970 M, ia mengabdikan diri sebagai profesor antropologi di Institut for Advanced Study di Princeton sampai pada akhir hayatnya tanggal 31 Oktober 2006 M.

Karya-karyanya meliputi kajian antropologi budaya, agama dan teori sosial, pembangunan pertanian, serta keanekaragaman etnis dan implikasinya pada dunia modern. Di antara publikasi karyanya yang menonjol adalah The Religion of Java (1960), Agricultural Involution (1963), Islam Observed (1968), The Interpretation of Cultures (1973), Negara (1980), dan Works and Lives (1980), Local Knowledge (1983).

Clifford Geertz mendasarkan karya-karyanya pada pengalaman dan hasil penelitian lapangannya di Indonesia dan Morocco selama hampir setengah abad. Bergabung dalam M.I.T. Indonesia Project, Clifford Geertz mengawali penelitian lapangannya secara intensif di Jawa dari tahun 1952 sampai dengan 1954. Selanjutnya selama beberapa dekade berikutnya Clifford Geertz bolak-balik ke Jawa dan Bali melakukan penelitian lapangannya. Untuk karya-karyanya mengenai Indonesia, khususnya Jawa dan Bali, yang mencerahkan ini, beliau menerima penghargaan dari pemerintah Indonesia pada tahun 2002.

\section{Kehidupan Sosial Keagamaan Masyarakat Mojokuto}

1. Interdependensi antara Agama dan Masyarakat

Perpektif sosiologis, terdapat hubungan interdependensi antara agama dan masyarakat, di mana keduanya saling pengaruh 
mempengaruhi satu sama lainnya. Joacheim Wach, menunjukkan adanya pengaruh timbal balik antara kedua faktor tesebut; pertama pengaruh agama terhadap masyarakat dan yang kedua, pengaruh masyarakat terhadap agama ${ }^{4}$. Agama Jawa dalam pandangan Clifford Geertz merupakan dampak sosiologis dari adanya hubungan interdepedensi dimaksud.

Clifford Geertz membuat kerangka analisis dengan mengklasifikasikan masyarakat Islam-Jawa ke dalam tiga varian, yaitu; abangan, santri, dan priyayi ${ }^{5}$ Pembacaan ini, oleh Geertz disandarkan pada asumsi bahwa pandangan dunia Jawa adalah agama Jawa yang dihadapkan pada sistem stratifikasi sosial di Jawa ${ }^{6}$. Artinya ketiga varian keberagamaan masyarakat Jawa dipengaruhi oleh tiga inti struktur sosial yaitu (desa, pasar dan birokrasi pemerintah). Dalam pengamatanya, tiga lingkungan yang berbeda (pedesaan, pasar dan kantor pemerintah) yang dibarengai dengan latar belakang sejarah kebudayaan yang berbeda ( yang berkaitan dengan masuknya agama serta peradaban Hindú dan Islam di Jawa) telah mewujudkan adanya; Abangan (yang menekankan aspek-aspek animistik), Santri (yang menekankan aspek-aspek Islam) dan Priyayi ( yang menekankan aspek-aspek hindú) ${ }^{7}$.

Berbeda dengan abangan yang diasumsikan sebagai bentuk religiousitas masyarakat desa, santri diasumsikan sebagai bentuk keberagamaan kaum pedagang (pasar). Tentu saja, pasar sebagai subsistem sosial utama masyarakat Jawa harus dipahami secara luas meliputi seluruh pulau. Untuk bagian terbesar, aspek perdagangan antar daerah berada di tangan orang Cina, sedangkan aspekyanglebih lokal berada di tangan orang Jawa. Sementara unsur perdagangan orang jawa versi Islam, bermula dari masuknya Islam ke pulau Jawa,

${ }^{4}$ Kahmad, Sosiologi..., h. 54

${ }^{5}$ Istilah Abangan, Santri, dan Priyayi bukan merupakan istilah yang diadaadakan oleh Clifford Geertz, tetapi diambil dari penggolongan yang diterapkan oleh masyarakat sendiri. Lihat dalam pendahuluan bukunya, The Religión of Java, terj. Aswab Mahasin: Abangan, Santri, Priyayi dalam Masyarakat Jawa, (Bandung: Dunia Pustaka Jaya, 1981), h. 8

${ }^{6}$ Menurut Clifford Geertz terdapat tiga inti struktur social di Jawa yaitu; desa, pasar dan birokrasi pemerintah, Lihat dalam pendahuluan bukunya, Ibid., h. 6

${ }^{7}$ Pasudi Suparlan dalam pengantar terhadap buku Clifford Geertz, Ibid.,h. vii 
sebagai bagian dari perkembangan perdagangan besar-besaran di laut Jawa. Meskipun kedatangan Belanda banyak mempengaruhi perdagangan orang Jawa yang telah lama berkembang di pelabuhanpelabuhan pantai utara, Surabaya, Gresik, Tuban dan lain-lain, tetapi kebudayaan dagang itu tidak mati sepenuhnya, malahan mampu bertahan hingga sekarang.

Santri yang merupakan salah satu dari substruktur sosial masyarakat Jawa, diasumsikan oleh Clifford Geertz sebagai golongan yang berusaha mengamalkan Islam sesuai dengan ajaran yang pertama datang kepada mereka. Geertz menyebut pula golongan ini adalah Islam yang berada dalam lingkaran fundamentalisme ajaran Islam. Tradisi keagamaan kalangan santri, tidak terbatas pada pelaksanaan yang cermat dan teratur atas pokok peribadatan Islam, tetapi juga suatu keseluruhan yang kompleks dari organisasi sosial, kedermawanan dan politik Islam ${ }^{8}$. Secara geografis, golongan santri biasanya berada dalam wilayah di sekitar pesisir pulau Jawa, yang menjadi titik tolak penyebaran Islam yang berasal dari Timur Tengah. Pemahaman mereka terhadap Islam cukup mendalam bahkan dalam pengamalan terhadap syariat Islam lebih pure (murni). Itu sebabnya, banyak muncul pesantren (tempat belajar mendalami agama Islam) di sepanjang pantura pulau Jawa. Dengan demikian, santri yang kategorinya adalah orang yang melaksanakan kewajiban agama secara cermat dan teratur dalam hal ini juga sesuai apabila disematkan pada masyarakat yang bermatapencaharian sebagai pedagang karena interaksinya dengan dunia luar yang cukup intens.

Berbeda dengan abangan dan santri, varian priyayi sebagai substruktur sosial Jawa, diasumsikan sebagai golongan bangsawan (aristokrat) yang dekat dengan kekuasaan, yang penghayatan agamanya banyak dipengaruhi oleh Hinduisme. Wilayah keraton atau kerajaan menjadi latar utama persebaran golongan ini. Tidak jauh berbeda dengan tipologi abangan, pada umumnya golongan priyayi hidup dalam lingkaran tradisi kejawen yang sangat kuat, mengingat istana merupakan pusat kekuatan budaya saat itu. Dalam mengamalkan Islam, golongan priyayi cenderung pada

${ }^{8}$ Keberagamaan varian Santri dipaparkan Clifford Geertz dalam bukunya bagian kedua, bab X sampai bab XVI , h. 165-301 
penggabungan ajaran agama dengan tradisi kejawen, bahkan juga tradisi Hinduisme dan Budhisme.

Berdasarkan klasifikasi demikian, dapat diambil gambaran bahwa penganut Islam di wilayah sekitar pesisiryang tergolong dalam kaum santri, yakni masyarakat di sekitar pantai utara (pantura) Jawa, mengamalkan Islam dengan tidak menonjolkan nuansa sinkretisme. Sebaliknya, masyarakat pedalaman yang kental dengan corak mistisisme Jawa beserta klenik di dalamnya dikategorikan sebagai Islam abangan yang mengamalkan Islam secara sinkretik. Begitu pula di lingkungan kerajaan, yang lebih cocok dalam klasifikasi priyayi, mengamalkan Islam dengan menggabungkannya terhadap Dengan demikian semakin jelas bahwa corak keberagamaan masyarakat Jawa diwarnai oleh keterpaduan antara budaya pendatang dan budaya lokal. Dan inilah yang disebut Clifford Geertz sebagai agama Jawa. Abangan yang mewakili penekanan pada aspek animistis dari Jawa dan secara luas dihubungkan dengan golongan petani; Santri, yang mewakili penekanan pada aspek Islam murni, dan umumnya dihubungkan dengan aspek dagang; Priyayi yang menekankan pada aspek-aspek Hindú dan dihubungkan dengan elemen birokratik. Semuanya merupakan tiga subtradisi utama dalam masyarakat Jawa ${ }^{9}$.

Dari paparan di atas dapatlah dipahami bahwa interdependensi antara agama (Islam) dan budaya lokal (animisme, hinduisme dan buddhisme) terlihat sekali dalam releigiousitas masyarakat Jawa (Mojokuto) yang terexspresikan dalam varian abangan, santri dan priyayi. Tarik menarik antara budaya pendatang pada satu sisi dan budaya lokal pada sisi lain, yang sama-sama kuatnya, berdampak pada terjadinya penyerapan dari dua unsur,yang pada perkembangannya membentuk budaya baru (agama khas Jawa). Meminjam teori fluiditas Rene Char, apabila dua budaya bertemu, yang terjadi adalah pelenturan-pelenturan nilai-nilai lama. Ketiga varian agama Jawa (abangan, santri dan priyayi) sebagaimana yang diketemukan Clifford Geertz, merupakan indikator nyata adanya fluiditas dimaksud. Ketika Islam bertemu dengan substruktur sosial desayangseratdengan kepercayaan tahayul, animismedan hinduisme

${ }^{9}$ Roland Robensons, Agama dalam Analisa dan Interpretasi Sosiologis, (PT. RajaGrafindo Persada, Yogyakarta, 1995), cet.4. h. 205-206. 
maka yang terjadi adalah peleburan antara Islam (sebagi agama asing ) dan budaya lokal yang pada perkembangannya terakumulasi dalam varian abangan. Demikian halnya, ketika Islam bertemu dengan substruktur birokrasi yang serat akan nilai-nilai tradisional kraton yang penuh dengan tata cara etiket kaum ningkrat, maka yang mengedepan adalah Islam ala varian priyayi, yang pada tataran tertentu masih mempertahankan praktek animisme dan Hinduisme sebagaimana varian abangan. Lain halnya dengan varian santri, ketika Islam dihadapkan pada substruktur sosial pasar yang serat dengan budaya pelayaran yang memungkinkan untuk secara mudah menggali dan menyerap Islam secara murmi, maka keberagamaan mereka lebih menampakkan unsur Islam secara murni. Dari sini jelaslah bahwa interdependensi antara agama (Islam) dan budaya lokal terjadi begitu intens di Jawa (Mojokuto).

\section{Agama: Konflik dan Integrasi}

Dalam masyarakat majemuk, agama dapat menjadi faktor pemersatu, sebagaimana juga dapat dengan mudah disalahgunakan sebagai alat pemecah belah. Agama pada satu sisi menciptakan ikatan bersama, baik antara anggota masyarakat maupun dalam kewajibankewajiban sosial yang membantu mempersatukan mereka. ${ }^{10}$ Tetapi di sisi lain, perasaan seagama saja tidak cukup untuk memciptakan perasaan memiliki kelompok atau kesatuan sosial. Maka harus ada faktor-faktor lain yang lebih memperkuat dan mempertahankan kohesi sosial. Dengan demikian agama mempunyai dua efek sekaligus, yaitu efek pemersatu dan sekaligus pemecah belah. ${ }^{11} \mathrm{Di}$ Jawa, dalam pengamatan Clifford Geertz, antara ketiga varian; abangan, santri dan priyayi, di samping terjadi ketegangan juga sering terjadi kohesi sosial yang cukup intens.

Di antara faktor- faktor yang mempertajam konflik antara lain;1). Konflik ideologis yang mendasar karena rasa tidak senang terhadap nilai-nilai kelompok lain.2). sistem stratifikasi sosial yang berubah dan mobilitas status yang cenderung untuk memaksakan adanya kontak di antara individu-individu dan kelompok-kelompok

${ }^{10}$ Elizabeth K Nottingham, Agama dan Masyarakat: Suatu Pengantar Sosiologi, (Jakarta: Rajawali Press, 1993), h. 42.

${ }^{11}$ Thomas F O'Dea, Sosiologi Agama Suatu Pengenalan Awal, Jakarta: Rajawali Press, 1987), h. 139. 
yang secara sosial dulunya sedikit banyak berubah. 3). Perjuangan mencapai kekuasan politik yang semakin tajam untuk mengisi kekosongan yang ditinggalkan oleh pemerintah kolonial, yang cenderung mencampur-aduk perbedaan-perbedaan agama dengan kepentingan politik. 4). Kebutuhan mencari kambing hitam untuk memusatkan ketegangan akibat perubahan sosial yang begitu cepat.

Secara Ediologis, kebencian abangan diarahkan kepada moralitas santri yang merasa dirinya "Sok Suci" (menganggap diri mereka sebagai komunitas yang lebih suci). Menurut kelompok abangan meskipunkelompoksantriyangkesehariaanya memakai"kerudung" (sebagai simbul ketaatan beragama), tetapi pada kenyataannya mereka berbuat mesum juga. Kebencian abangan terhadap santri demikian jelas sekali diutarakan dalam pantun yang berkembang di kalangan masyarakat abangan "mendung-mendung cap gomek, kudung-kudung digawe lemek". Senada dengan stetemen abangan, kelompok priyayi juga menganggap bahwa kesalehan kaum santri hanyalah kesalehan semu, tidak menampilkan dengan kondisi sebenarnya. Dikatakan, meski santri melakukan ritual keagamaan (Haji) yang seharusnya berprilaku baik, namun pada kenyataannya prilaku mereka justru tidak menampilkan sebagai seorang yang sholeh ${ }^{12}$. Tidak kalah serunya, kaum santri menuduh kaum abangan sebagai "peyembah berhala"dan menuduh priyayi tidak dapat membedakan dirinya dengan Tuhan (kesombongan yang besar dosanya) ${ }^{13}$. Adapun konflik antar priyayi dan abangan tampak relatif agak halus, ketegangan paling nampak terlihat dalam masalah status. abangan menuduh priyayi sebagai pemerintah yang eksploitatif. Demikian halnya sebaliknya, priyayi sering menuduh "orang desa" tak tahu tempatnya yang layak dan karenanya mengganggu keseimbangan organisasi masyarakat, mempersalahkan mereka sebagai berlamunan besar dan gagal meniru-niru gaya priyayi ${ }^{14}$.

Adapun hal-hal yang meredakan konflik antara lain; a). perasaan memiliki satu kebudayaan yang menekankan pada kesamaan yang dipunyai orang Jawa, ketimbang pada perbedaannya.

\footnotetext{
${ }^{12}$ Robenson, Agama dalam..., h. 209, dan Clifford Geertz, Santri..., h. 477-478

${ }^{13}$ Ibid., h. 211.

${ }^{14}$ Geertz, Santri..., h.480-481
} 
b). kenyataan bahwa pola-pola keagamaan tidak diungkap secara langsung dalam bentuk-bentuk sosial, secara murni dan sederhana, melainkan melalui proses yang rumit, hingga komitmen keagamaan dan komitmen lanilla-terhadap kelas, tetangga dan sebagainya cenderung seimbang, sehingga muncullah berbagai individu dan kelompok "tipe campuran" yang bisa berperan sebagai perantara. c). toleransi umum yang didasarkan atas statu "relativismo kontekstual" yang menganggap nilai-nilai tertentu sesuai dengan konteksnya dan dengan demikian memperkecil "misiónisasi". d). Pertumbuhan mekanisme yang mantap menuju kepada bentuk-bentuk integrasi sosial yang majemuk dan nonsinkritis yang di dalamnya orangorang memiliki berbagai pandangan sosial dan nilai dasar yang berbeda secara radikal dapat bergaul dengan cukup baik satu sama lain untuk menjaga agar masyarakat tetap berfungsi ${ }^{15}$.

Dengan adanya faktor-faktor itulah maka masyarakat jawa, baik kalangan abangan, santri dan priyayi dalam batas-batas tertentu sering membawur satu sama lain dalam beberapa even; slametan ${ }^{16}$, peringatan hari besar nasional dan riyoyo (hari besar Islam). Bahkan yang terakhir ini ( Riyoyo) hampir merupakan sebuah agama universal Jawa artinya semua lapisan masyarakat ikut merayakan secara serentak bersama-sama.

Dari gambaran uraian di atas dapatlah dipahami bahwa paling tidak terdapat tiga faktor utama penyebab terjadinya konflik; Ediologi, stratifikasi sosial dan politik. Sedangkan yang menjadi faktor utama terjadinya integrasi adalah; adanya kesadaran akan kesatuan kebudayaan, kenyataan artikulasi kebudayaan dan sistem sosial di mana pun bahwa pola-pola nilai tidak diinstitusionalisasi secara langsung, murni dan tanpa gangguan, melainkan terintegrasi ke dalam sistem sosial yang terdeferensiasi dengan cara sedemikian rupa, hingga struktur yang dihasilkan tidak mencerminkan organisasi kebudayaannya dengan cara yang sederhana.

${ }^{15}$ Robenson, Agama dalam..., h. 207-208. Lihat juga Geertz, Santri..., h. 476477

${ }^{16}$ Dikatakan Clifford Geertz, semua orang jawa, demi menjaga rukun tetangga, hampir tak seorang pun yang dapat menghindar dari slametan, Ibid., h. 490 


\section{Analisis Pemikiran Clifford Geertz}

Perspekstif Clifford Geertz, Abangan, Santri dan Priyayi, masing-masing merepresentasikan peran dan pengamalan keberagamaan yang sangat berbeda. Kelompok abangan, mempresentasikan sebagai kelompok yang secara konsisten mempertahankan kepercayaan-kepercayaan lokal yang telah menjadi tradisi sejak nenek moyang masyarakat Jawa, animisme. Sementara Santri, dianggap sebagai kelompok yang mampu merepresentasikan agama secara benar berdasarkan tatanan syariah. Karenanya Santri dianggap Geertz sebagai yang paling islami dalam struktur masyarakat Jawa. Sedangkan kelompok priyayi merepresentasikan tradisi mistik yang lebih diyakini sebagai warisan dari keagamaan Hindu dan Budha sebelum Islam. Ekstremnya, meski dianggap representasi kelompok beragama masyarakat Jawa yang paling Islami, santri pada kenyataannya masih sangat dipengaruhi oleh kekuatan kepercayaan hindu dan budha yang telah terlebih dahulu melekat pada kebudayaan masyarakat Jawa. Tesis demikian tentu saja mengundang para pakar menjadi tertantang untuk mengkritisi.

Kritik yang cukup tajam atas karya Geertz antara lain disampaikan oleh Marshall Hodgson dalam karyanya "the Venture of Islam". Meski tetap memandang karya Geertz sebagai karya penting dalam studi Asia Tenggara, Marshall Hodgson mempertanyakan kesimpulan Geertz yang cenderung meragukan keislaman masyarakat Jawa. Geertz dinilai menginterpretasikan kebudayaan Jawa dengan term syariah minded yang menutup peluang pembacaan terhadap unsur lain seperti tasawwuf, mistik Islam. ${ }^{17}$ Sarjana Barat Lain seperti Eickelman dan Roof menyuarakan pandangan yang sama tentang problem penafsiran Jawa ini; akibat kurangnya pemahaman tentang Islam. ${ }^{18}$

Senada dengan Marshall Hodgson, Mark Woodward dengan jelas menolak pandangan Geertz bahwa Jawa tidaklah Islami. Bahkan bagi Woodward masyarakat Jawa merupakan pemeluk Islam yang paling kreatif menghubungkan kebudayaan dan struktur sosial

${ }^{17}$ Hendro Prasetyo "Mengislamkan" Orang Jawa: Antropologi Baru Islam Indonesia”, Jurnal Islamika No 3 edisi Januari-Maret, (Jakarta, 1994), h. 77

${ }^{18} \mathrm{Ibid}$., h. 81 
terdahulunya dengan Islam sebagai unsur yang "baru" dalam sebuah struktur kebudayaan. Tradisi intelektual dan spiritual Islam di Jawa merupakan tradisi kreatif. Bagi Woodward terdapat kewajaran mengapa Islam Jawa sangat berbeda dengan keislaman Timur Tengah atau Jazirah Arab, letak geografis yang sangat menyulitkan komunikasi dan interaksi antar keduanya menyebabkan Islam di Jawa berkembang dengan model dan coraknya sendiri tanpa harus menjadikan Arab sebagai patokan dominan. Lebih dari itu, Profesor Bachtiar mengkritisi bahwa penggunaan istilah abangan, santri dan priyayi untuk mengklasifikasikan masyarakat Jawa dalam golongan-golongan agama tidaklah tepat. Sebab ketiganya tidak bersumber pada satu sistem klasifikasi yang sama, abangan dan santri merupakan penggolongan yang dibuat berdasarkan tingkat ketaatan dalam beribadah sementara priyayi merupakan suatu penggolongan berdasarkan tingkat sosial.

Kritikan yang tak kalah tajamnya datang dari Zaini Muhtarom dalam laporan penelitiaannya yang diberi judul "Santri dan Abangan di Jawa". Menurut pengamatannya, pengklasifikasian orang jawa menjadi abangan, santri dan priyayi sebagaimana yang dilukiskan Clifford Geertz mengacaukan dan menyesatkan sebab tidak didasarkan pada kretiria yang konsekuen. Ia mengacaukan dua pembagian yang termasuk susunan yang berlainan, serta mencampuradukkan pembagian horizontal dan vertikal, sementara ia melupakan perbedaan antara stratifikasi horizontal dan vertikal dalam masyarakat jawa. Dengan merujuk pada stratifikasi pola Kuntjaraningkrat, Muhtarom, menyebutkan bahwa istilah santri dan abangan telah menunjukkan dua varian relijius dalam kebudayaan Jawa, sementara istilah priyayi tidak menunjukkan tradisi religius apapun juga ${ }^{19}$.

Senada dengan para pakar di atas, Zainuddin Maliki dalam penelitian tentang Agama dan Kekuasaan, meski menggunakan terminologi "Agama Priyayi" ${ }^{20}$ memberikan gambaran lain yang jauh berbeda dari perspektif Clifford Geertz. Karena pada realitanya

${ }^{19}$ Koentjaraningrat, Sejarah..., h. 89-91

${ }^{20}$ Priyayi merupakan komunitas yang secara representative mewakili kelompok aristokrasi jawa. Makalah Roziqin, Agama dan Kekuasaan : Studi atas Kitab “Agama Priyayi” karya Zainuddin Maliki. 
terdapat priyayi yang santri dan sebaliknya ada santri yang priyayi dan abangan, maka penggolangan demikian tidaklah terlalu tepat. Variasi Agama jawa yang ditemukan Andrew Betty di Banyuwangi menginformasikan betapa variasinya agama Jawa ${ }^{21}$

Meski didasarkan pada pandangan masyarakat Jawa, namun generalisasi tersebut pada kenyataannya sangat problematis ketika digeneralisir sebagai tipologi masyarakat jawa secara keseluruhan. Setidaknya studi Robert Hefner yang memberikan perhatian pada masyarakat yang dianggap tidak Islami di Tengger yang menemukan bukti bahwa masyarakat Tengger sangat dipengaruhi oleh unsurunsur Islam..$^{22}$ Atau studi Nakamura di Kotagede Yogyakarta dengan fokus keberadaan masyarakat Muhammadiyah yang menafsirkan kentalnya unsur-unsur Islam dalam sistem kepercayaan masyarakat tersebut. Artinya studi Geertz yang berlokasi di Mojokuto dan Nakamura di Kotagede Yogyakarta memiliki kemungkinan sangat luas untuk menghasilkan pandangan dan penafsiran yang berbeda dikarenakan perbedaan cara pemahaman kejawaan dan keislaman dalam kedua masyarakat yang berbeda secara geografis.

\section{E. Sumbangan Clifford Geertz dalam Studi Agama}

Sebagaimana pengamatan Daniel L. Pas, ide dan gagasan Clifford Geertz tentang budaya dan agama berkembang di bawah dua pengaruh utama; tradisi Antropologi Amerika yang independen dan kuat dan perspektif tentang ilmu sosial yang dijumpai saat belajar di Havard University dibawah bimbingan langsung teoritisi terkemuka Talcott Parson. Dalam bidang antropologi ia banyak dipengeruhi oleh antropolog Boas, Kroeber dan Benedit ${ }^{23}$, sementara dalam bidang Sosiologi banyak dipengaruhi oleh Talcott Parson dan Max Waber. ${ }^{24}$ Keterpengaruhan demikian tampak sekali ketika Clifford Geertz meneliti masyarakat Mojokuto. Barangkali

${ }^{21}$ Makalah Husnul Qodim, Variasi Agama di Jawa karya Andew Betty.

${ }^{22}$ Robert W. Hefner, "Geger Tengger: Perubahan Sosial dan Perkelahian Politik. (Yogyakarta: LKiS, 1999).

${ }^{23}$ Mereka menegaskan bahwa dalam studi lapangan, mereka tidak hanya meneliti sebuah masyarakat, tetapi meneliti ide, adat istiadat, sikap, symbol dan institusi yang lebih luas di mana masyarakat hanyalah suatu bagian. Lihat. Daniel L. Pals, Seven ..., h. 404.

${ }^{24}$ Ibid., h. 405 
karena kentalnya keterpengaruhan dua tradisi penelitian ini, maka sulit sekali mengklasifikasikan model pendekatan mana yang secara spesifik digunakan Clifford Geertz dalam penelitaian lapangan. Dan untuk sementara pakar tidak memilah secara tegas antara pendekatan Sosiologis dan Antropologis, karena perbedaan hanya bersifat verbal. Bahkan dalam perkembangan dewasa ini pendekatan demikian semakin menjadi trend dalam mengkaji keberagaman masyarakat yang sering disebut sebagai pendekatan interdisipliner. Untuk sebagian besar orang Eropa memahami arti "masyarakat" dan "antropologi masyarakat" sebagai sesuatu yang agak dekat kepada apa yang diartikan oleh antropolog Amerika dengan istilah "budaya" dan "antropologi budaya" 25 Sebaimana dijelaskan bahwa pemetaan tersebut bukan rekayasa dia (sebagai peneliti) tetapi atas dasar pengakuan masyarakat sendiri, di mana fakta sosial dibiarkan berbicara sendiri atas dirinya. Dengan demikian menunjukkan betapa Clifford Geertz menggunakan pendekatan "thick diskription" bukan sekedar pendekatan "thin diskription" yang secara ilmiah dikenal sebagai pendekatan "Hermunitik Cultural atau Cultural Interpretation"26. Oleh karenanya tidaklah berlebihan kiranya jika dikatakan bahwa Clifford Geertz termasuk pada era metodologi modernisme yang, pada tataran tertentu, masih dapat digunakan dalam menstudi keberagamaan manusia dewasa ini.

\section{F. Kesimpulan}

Dari Kajian atas penelitian Clifford Geertz tentang agama jawa dapat diambil suatu pemahaman bahwa Clifford Geertz menemukan fakta sosial adanya tiga varian agama Jawa yaitu abangan, santri dan priyayi, yang meskipun secara kualitas berbeda ketiganya masih memperlihatkan nuansa tradisi Jawa, sebab santri dalam batas-batas tertentu yang agak ketat, pada kenyataannya masih mentolerir tradisi Jawa. Ketiga varian, baik abangan, santri maupun priyayi saling mengejek dan mengklaim bahwa komunitasnya yang paling baik dan benar. Statifikasi sosial

${ }^{25}$ Koentjaraningrat, Sejarah..., h. 88-89.

${ }^{26}$ Litle John, Theories of Human Communications, Materi Kuliah Prof. DR. Asep Samuh. Lihat juga Ahmad Fedyani Saifuddin, Antropologi Kontemporer: Suatu Pengantar Kritis Mengenai Paradigma, (Jakarta: Prenada Media Grup, 2005), h. 43 
yang diketemukan Clifford Geertz dirasakan mengganggu para antropolog sehingga mengundang kritik yang sangat tajam.

Betapa pun Clifford Geertz mendapatkan tantangan yang cukup telak dan bertubi-tubi dari berbagai kalangan akademisi, meski cukup menggoyahkan bangunan teorinya (strativikasi abangan, santri dan priyayi), namun pada kenyataannya tidak sampai pada taraf menurunkan eksistensinya sebagai pakar antropologi. Berbagai kritikan tersebut justru memperkokoh posisinya baik sebagai teoritisi sosiologi maupun antropologi budaya. Dalam penilitian Agama Jawa Clifford Geertz meski lebih bernuansa antropologis dengan pendekatan "cultural interpretative" namun nuansa sosiologisnya masih cukup tampak terutama dalam pendekatan sosiologis masalah makna. Boleh jadi Clifford Geertz mulai meletakkan metodologi "interdisipliner".

Pola pendekatan Clifford Geertz dapat dikategorikaan metodologi modernisme. Meski temuannya tentang ketiga varian agama jawa tampak kurang kokoh setelah menuai kritik dari para pakar, namun pendekatan "cultural interpretative" yang diusung dalam batas-batas tertentu masih dapat dipakai dalam menstudi keberagamaan masyarakat dewasa ini. Prosesi ritus penggantian nama Clifford Geertz menjadi Kartopawiro' memperjelas betapa dia konsens menggunakan pola pendekatan partisipan untuk menggali data seobyektif mungkin. []

\section{Daftar Pustaka}

DH., Burger, Structural Changes in Javanist: The Supra Village Sphere, terj. H. Palmier. Itacha, New York, Modern Indonesia Project, Cornell University, 1956

Geertz, Clifford, Abangan, Santri, Priyayi dalam Masyarakat Jawa, terj. Aswab Mahasin, Bandung: Dunia Pustaka Jaya, 1981.

Hefner, Robert W., Geger Tengger: Perubahan Sosial dan Perkelahian Politik, Yogyakarta: LKiS, 1999.

Kahmad, Dadang, Sosiologi Agama, Bandung: Penerbit PT Remajarosdakarya, 2002, cet.2, 
Koentjaraningkrat, Sejarah Antropologi, I, Jakarta UI Press, 1987

Majalah Ilmu-ilmu Sastra Indonesia, I, no.2, September 1963 Murdock, George Peter, Viking Found Publication in Anthropologi, Chicago: Quardrangle Books, 1960.

Nottingham, Elizabeth K., Agama dan Masyarakat: Suatu Pengantar Sosiologi, Jakarta: Rajawali Press, 1993.

O’Dea, Thomas F., Sosiologi Agama Suatu Pengenalan Awal, Jakarta: Rajawali Press, 1987.

Pals, Daniel L. dalam, Seven Theories of Religion, Jogjakarta: Penerbit Qalam, 2001, cet.1.

Prasetyo, Hendro, "Mengislamkan" Orang Jawa: Antropologi Baru Islam Indonesia”, Jurnal Islamika No 3 edisi Januari-Maret. Jakarta, 1994

Robensons, Roland, Agama dalam Analisa dan Interpretasi Sosiologis, Jakarta: PT. RajaGrafindo Persada, cet.4, 1995.

Saifuddin, Ahmad Fedyani, Antropologi Kontemporer: Suatu Pengantar Kritis Mengenai Paradigma, Jakarta, Prenada Media Grup, 2005 